\title{
Evaluation of Antifungal Activity of Chitosan Nanoparticles Against Fusarium Solani Phytopathogenic Fungi in in Vitro and in Vivo Assays
}

\section{Pamela R. Avila}

Universidad El Bosque

Graciela Juez Castillo ( $\square$ juezgraciela@unbosque.edu.co )

Universidad El Bosque https://orcid.org/0000-0003-2448-4380

Carel E. Carvajal

Universidad El Bosque

\section{Research Article}

Keywords: Chitosan nanoparticles, Fusarium solani, Solanum lycopersicum, Transmission electron microscopy, ultrastructure

Posted Date: April 26th, 2021

DOl: https://doi.org/10.21203/rs.3.rs-362614/v1

License: (c) (1) This work is licensed under a Creative Commons Attribution 4.0 International License.

Read Full License 


\section{Abstract}

Fungal diseases are a current problem in agriculture causing significant losses in several crops whereby its prevention and treatment is of utmost importance. The Chitosan nanoparticles (ChNPs) were evaluated for their antimicrobial activity against the phytopathogen Fusarium solani. The chitosan concentration in nanoparticles that showed antifungal activity was $2.0 \mu \mathrm{g} / \mathrm{mL}$. ChNPs showed to be a potential antifungal candidate with applications in phytosanitary control. Transmission electron microscopy (TEM) results showed damage to the fungal cell wall and membrane caused by the nanoparticles interaction with these structures affecting fungal growth and development in in vitro as in in vivo assay where microscopy demonstrated the internalization of nanoparticles aggregates within plant root cells cytoplasm up to 45 days. Therefore ChNPs nanoparticles could be an alternative method for diseases caused by Fusarium solani instead of chemical fungicides commonly used for treating tomato root rot.

\section{Full Text}

Due to technical limitations, full-text HTML conversion of this manuscript could not be completed. However, the manuscript can be downloaded and accessed as a PDF.

\section{Figures}




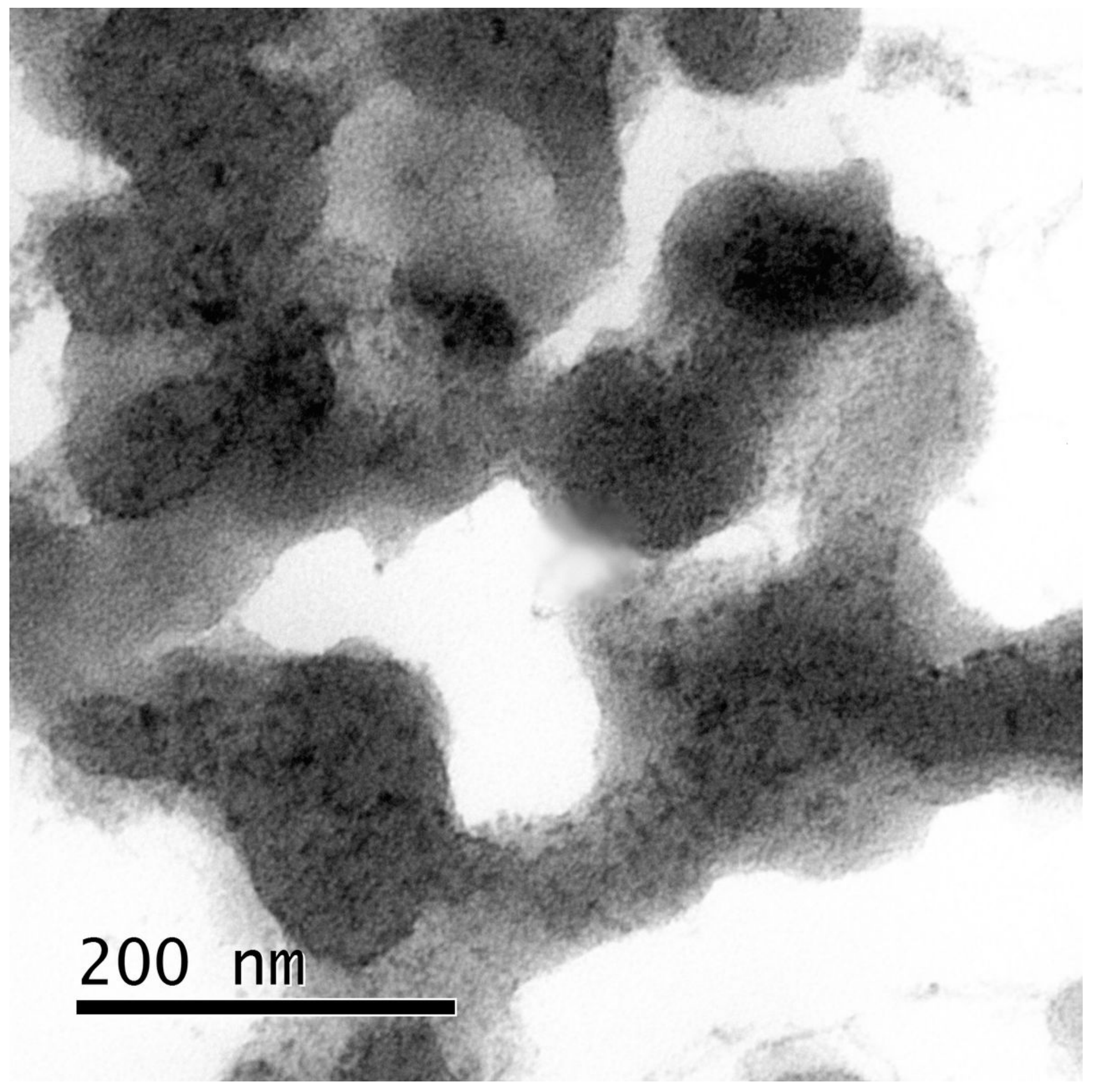

Figure 1 


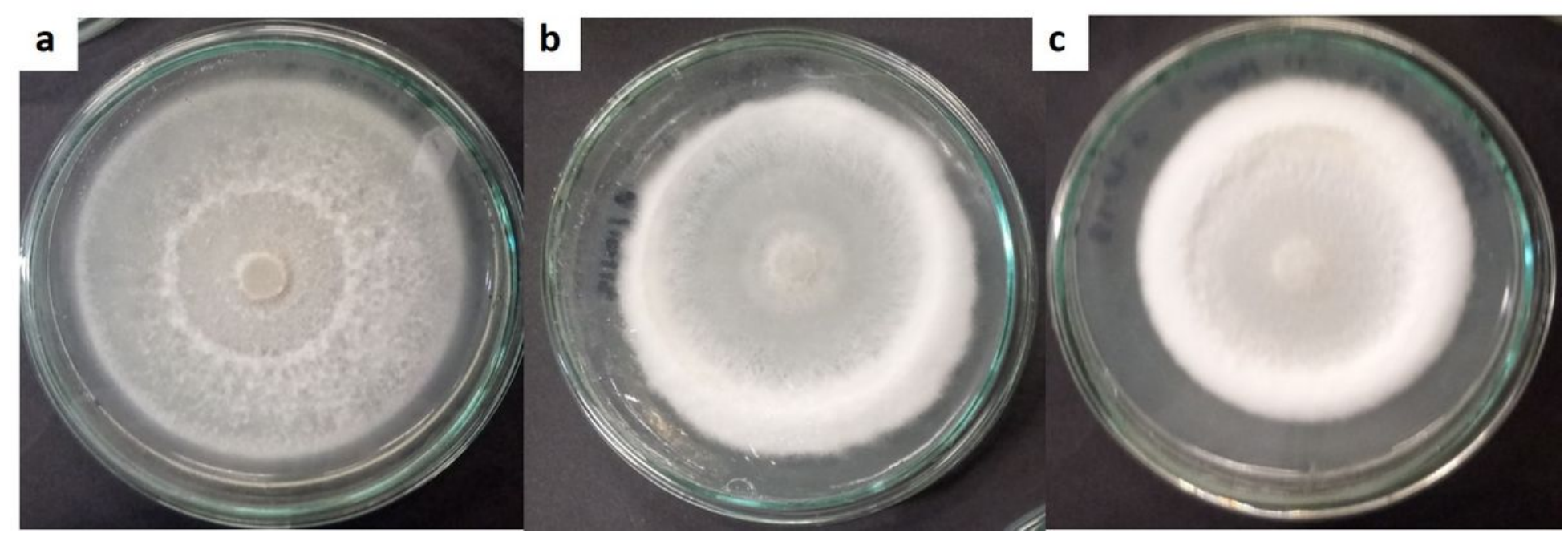

Figure 2

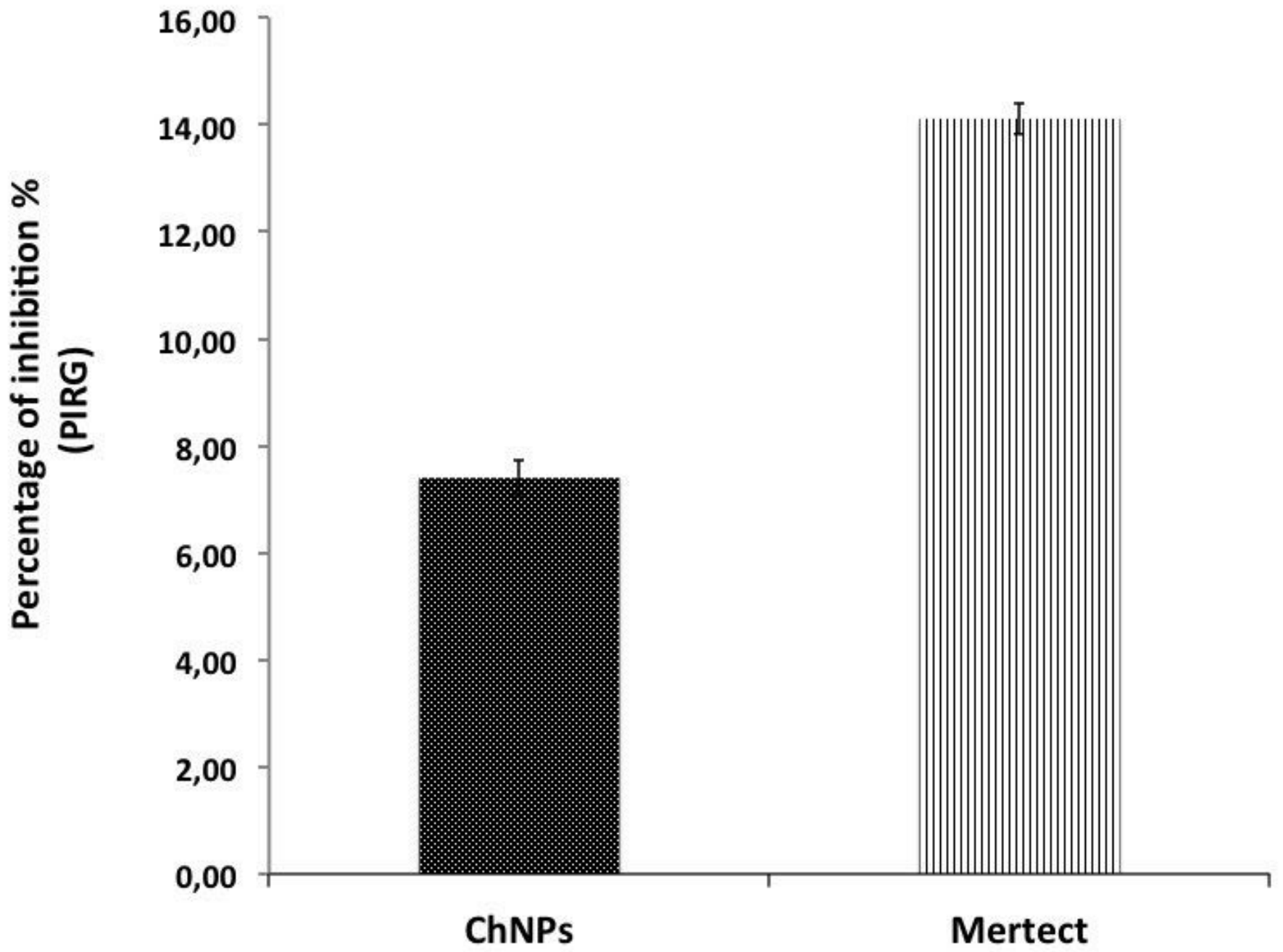

Figure 3 


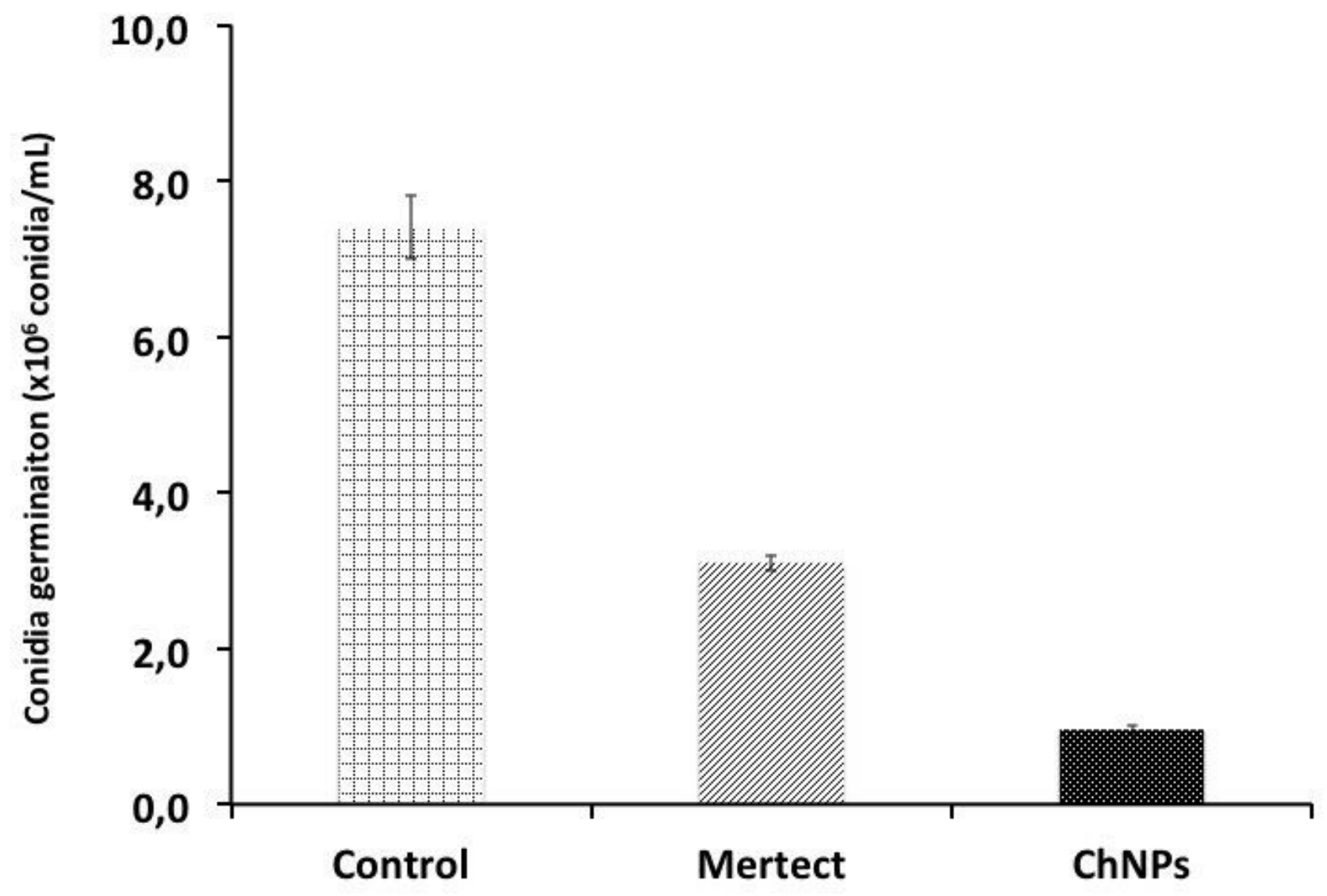

Figure 4 

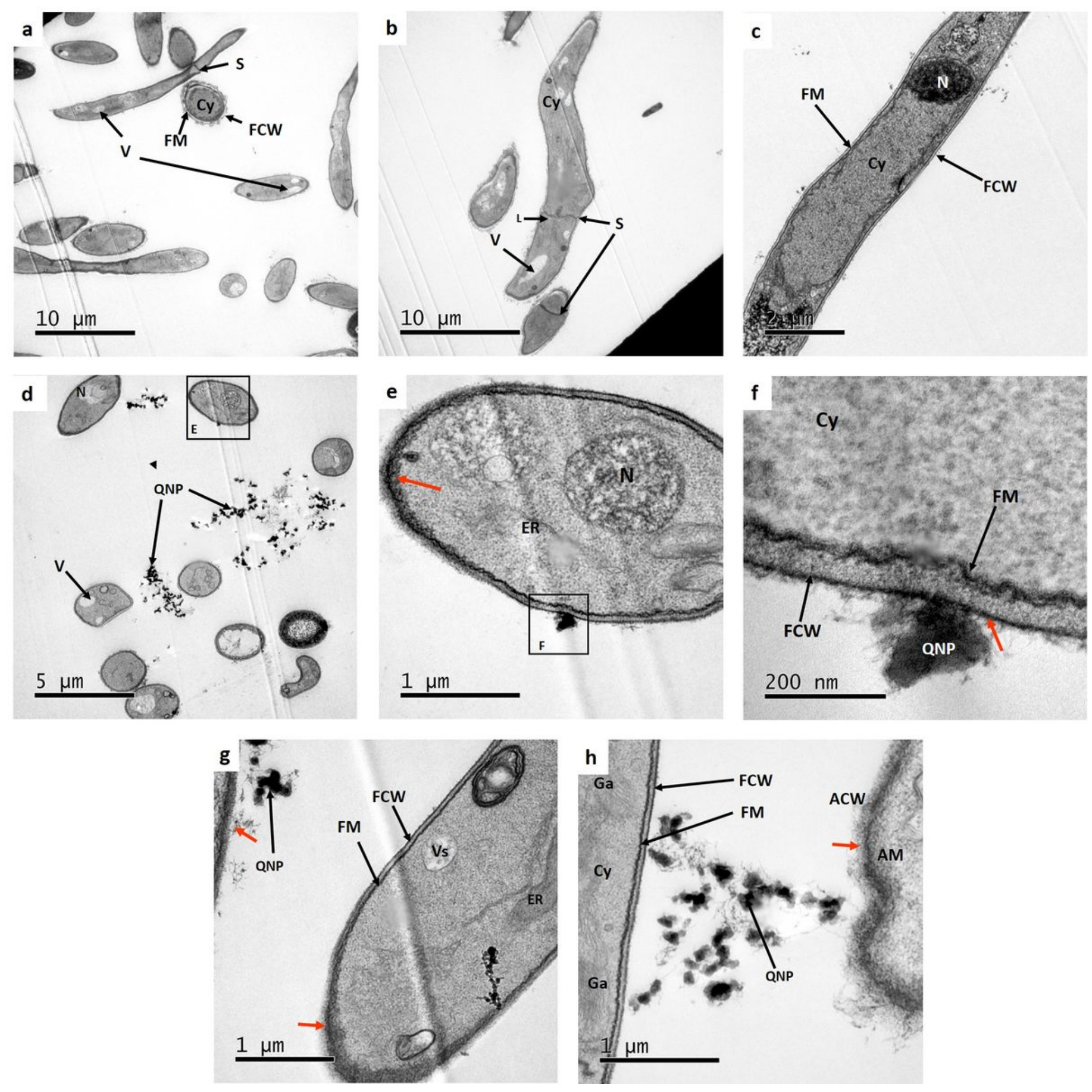

Figure 5 

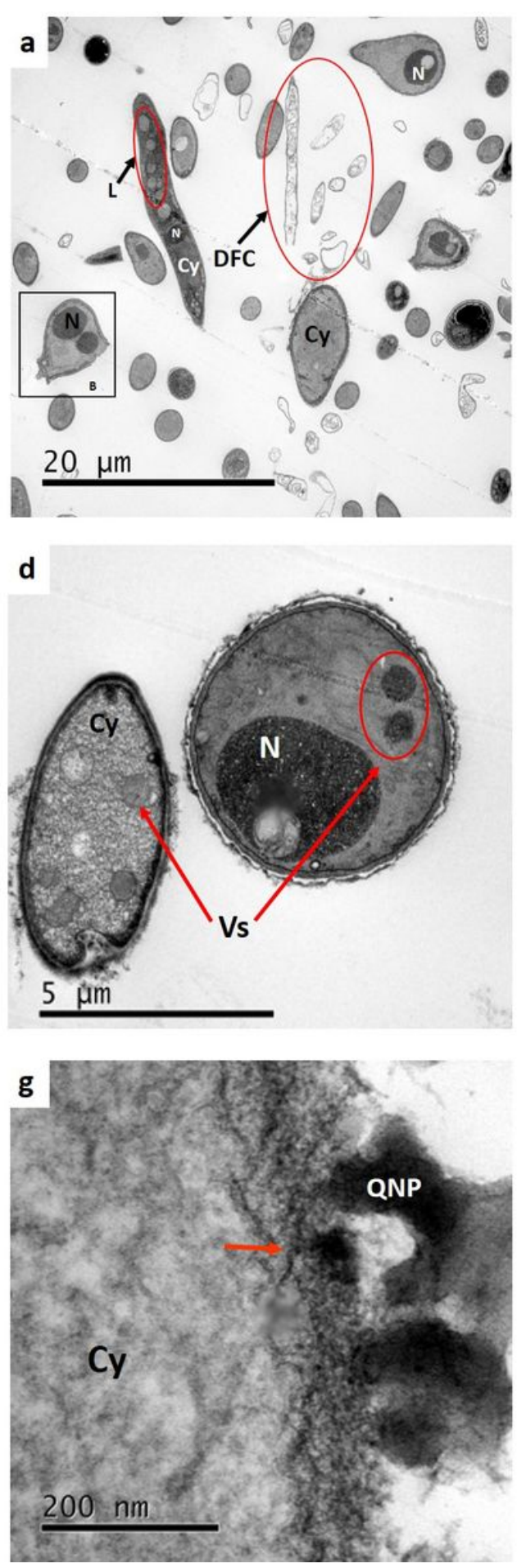
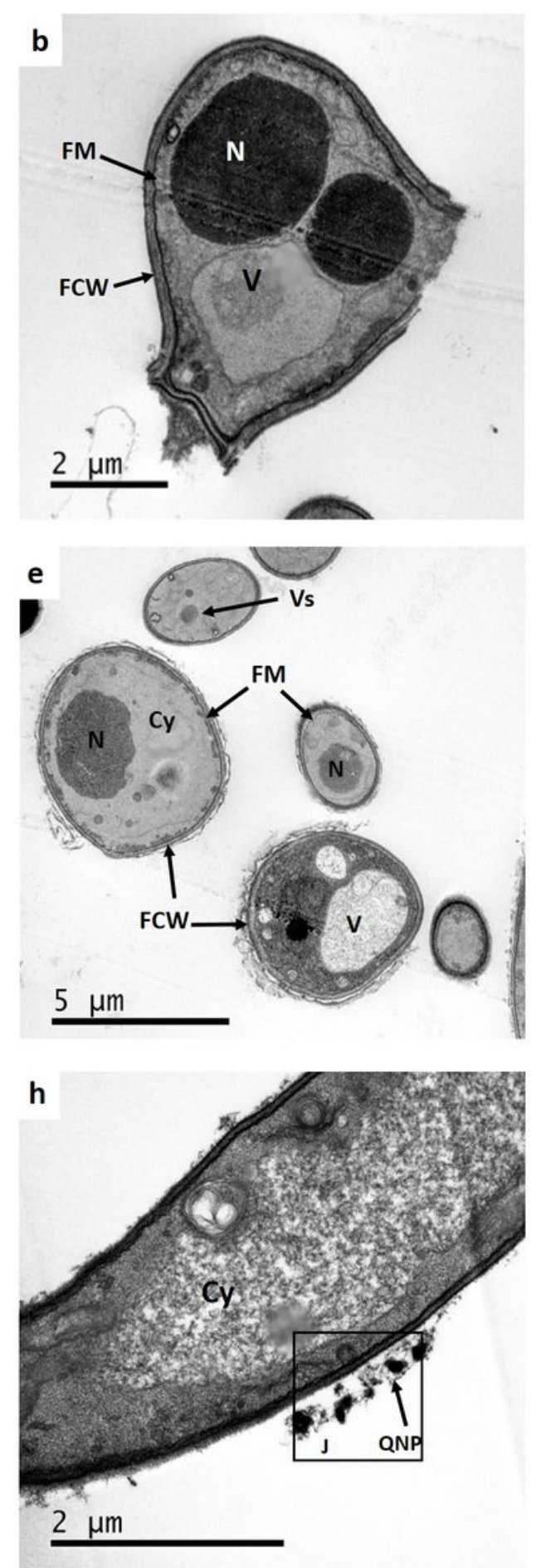

c
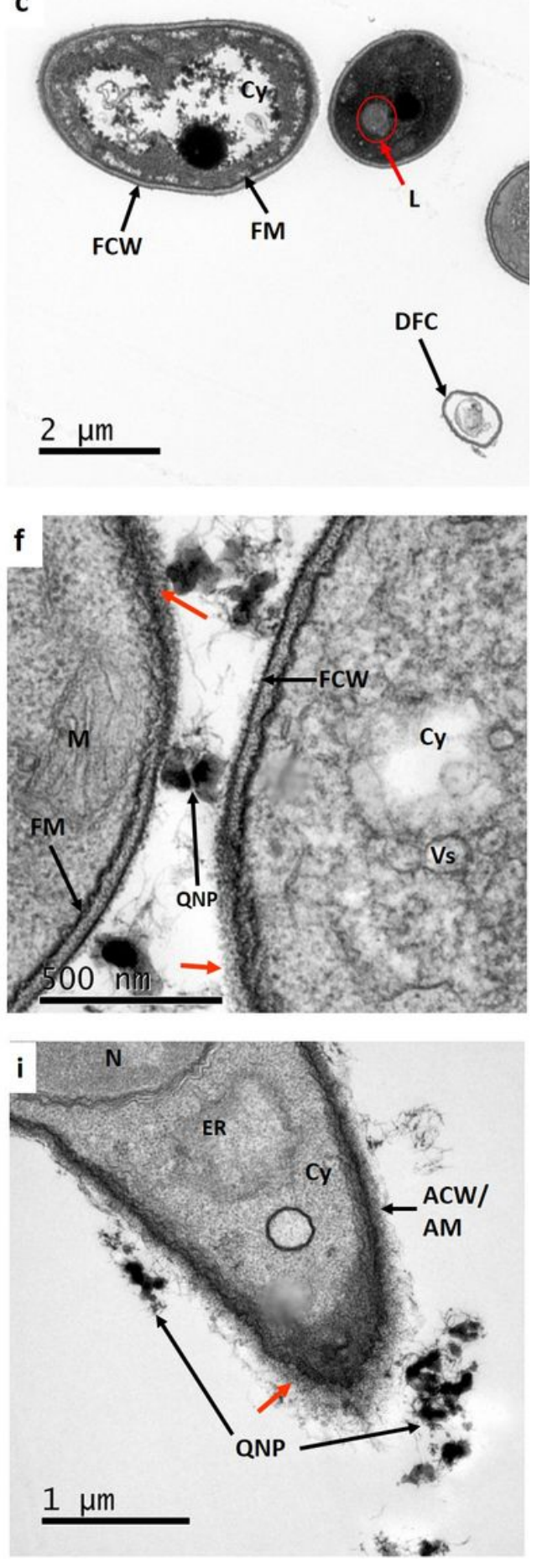

Figure 6 

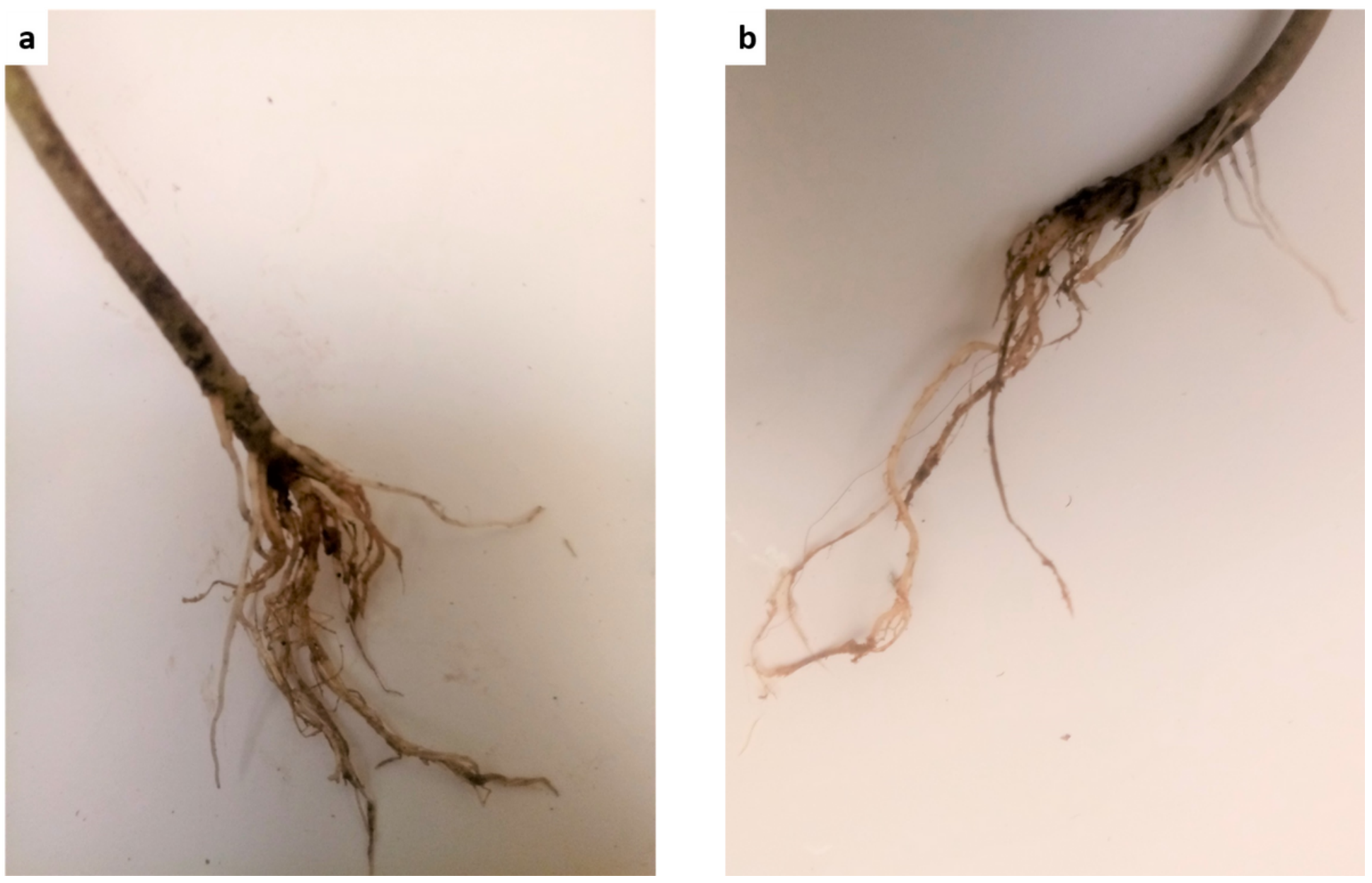

Figure 7 

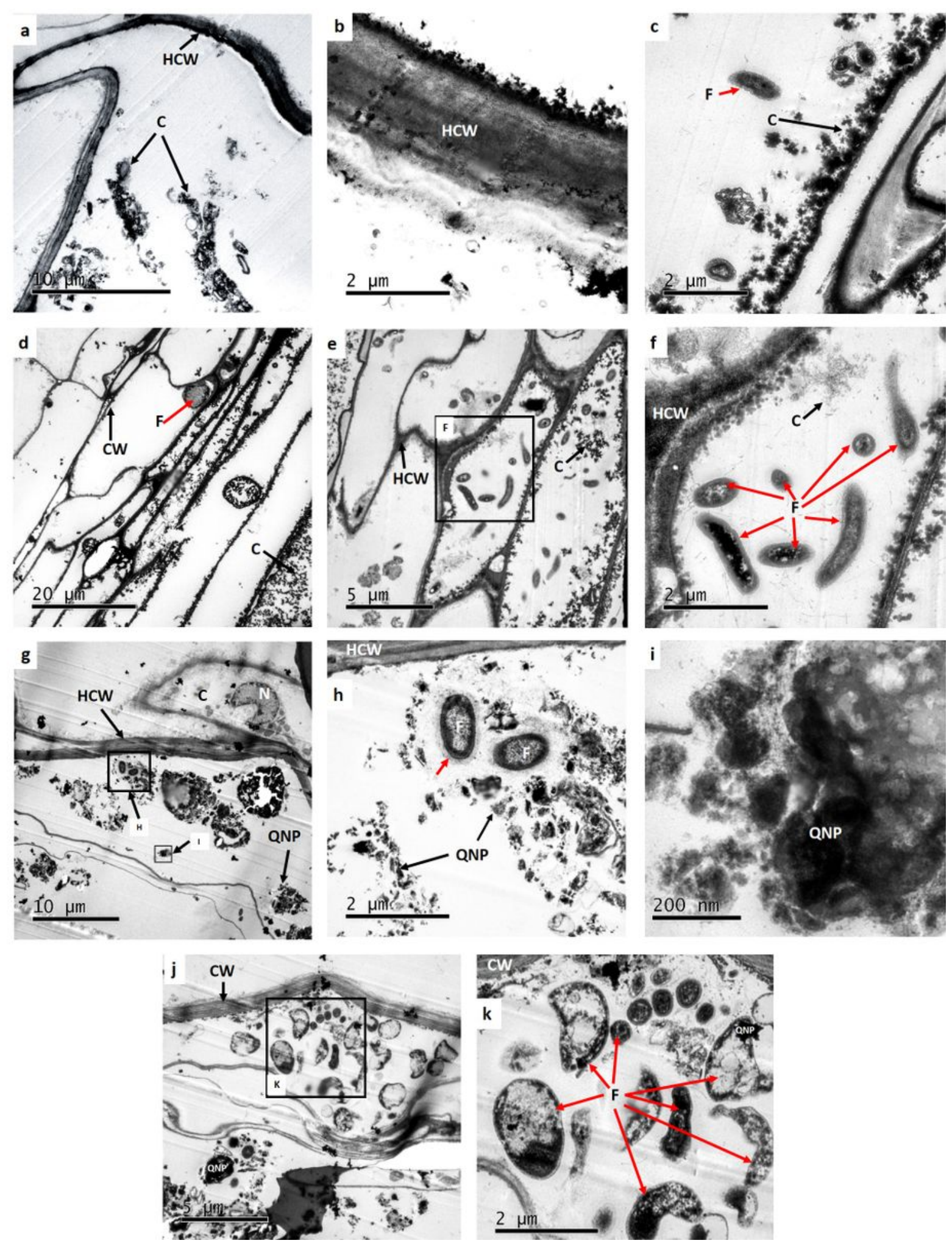

Figure 8 


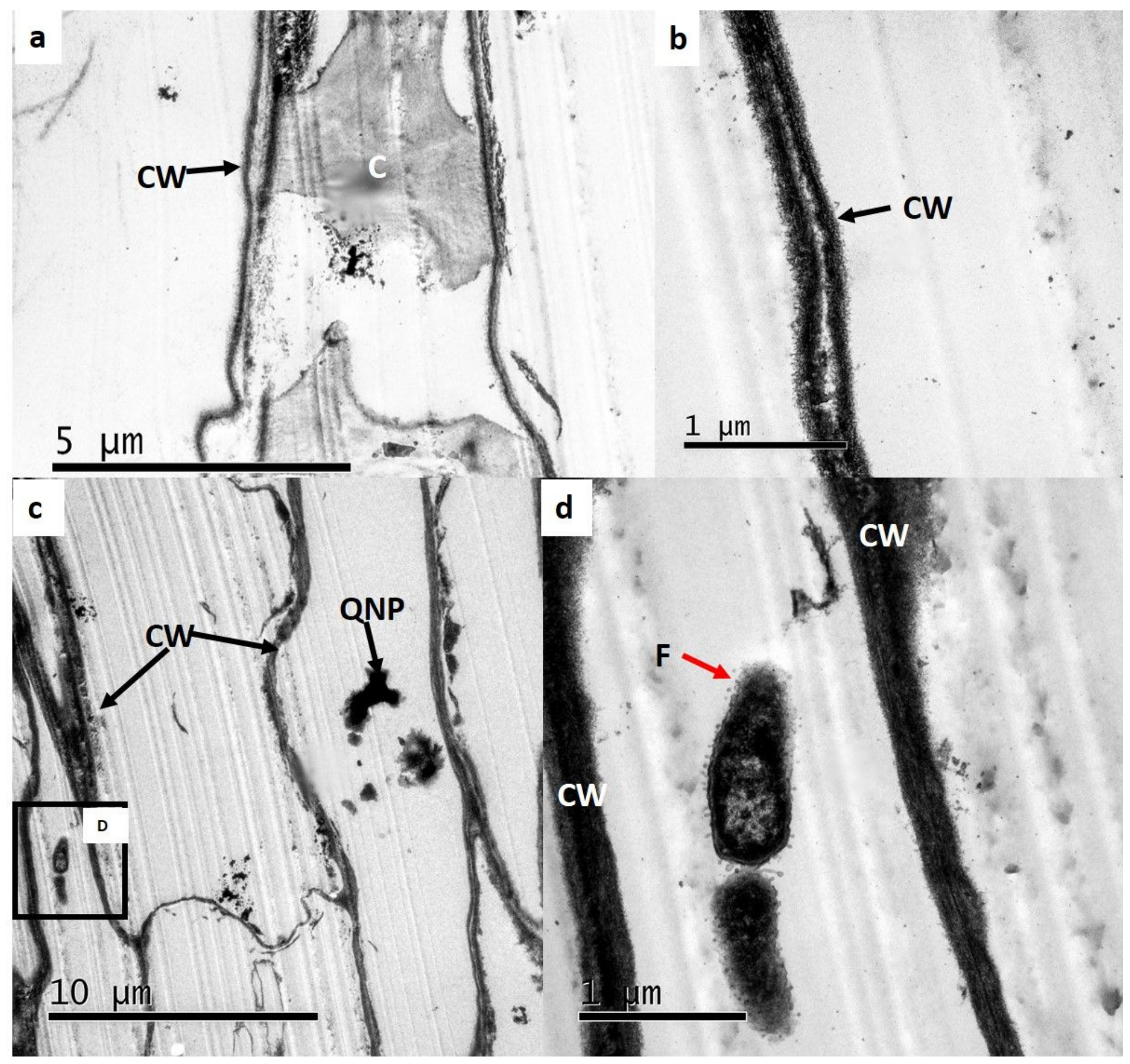

Figure 9 


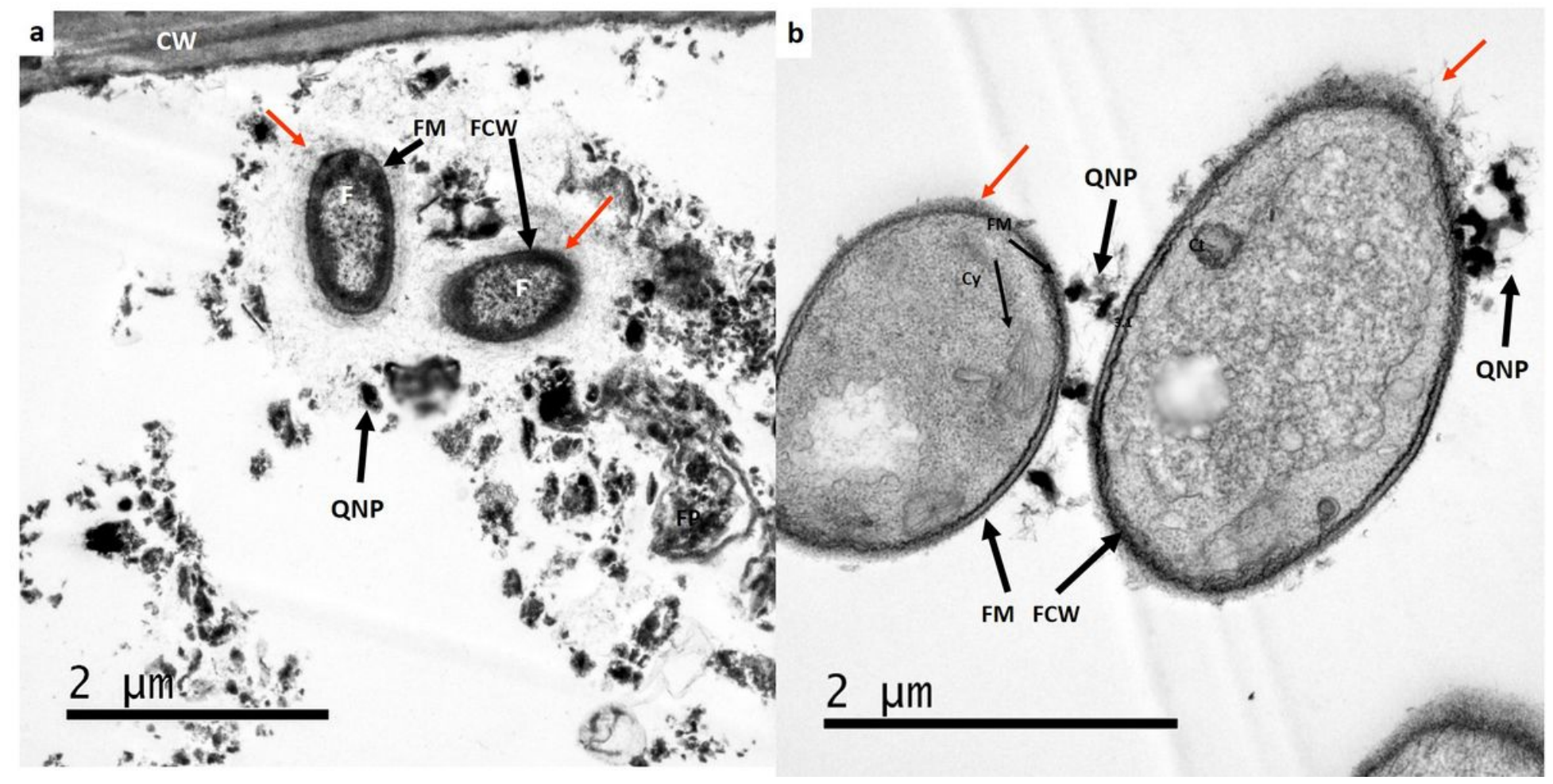

Figure 10 